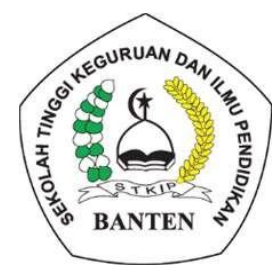

Tulip 10 (2) (2021) : 85-91

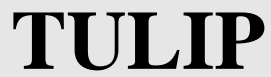

(Tulisan Ilmiah Pendidikan)

Jurnal IImiah Keguruan Dan IImu Pendidikan

TULIP http://journal.stkipbanten.ac.id/index.php/tulip

\title{
MODEL PEMBELAJARAN QUANTUM LEARNING TERHADAP BERPIKIR KRITIS SISWA PADA MATA PELAJARAN PPKn
}

\author{
Ahmad Yanuar Syauki ${ }^{1}$, Muhtaji $^{2}$, dan Iroh Napiroh ${ }^{3}$ \\ ${ }^{1}$ Sekolah Tinggi Keguruan dan Ilmu Pendidikan Banten \\ ${ }^{2}$ Sekolah Tinggi Keguruan dan Ilmu Pendidikan Banten \\ ${ }^{3}$ Mahasiswa Pendidikan Pancasila dan Kewarganegaraan \\ Penulis Korespondensi: aysyauki@yahoo.com ${ }^{1}$, muhtajiaji3@gmail.com ${ }^{2}$, \\ irohn14@gmail.com ${ }^{3}$ \\ Artikel : \\ Model Pembelajaran Quantum Learning \\ Penerima: Juli 2021 \\ Diterima: Agustus 2021 \\ Dipublikasikan: September 2021
}

\begin{abstract}
Education can be defined as a process or activity that aims to make human behavior that experiences education change. Lately, Education has made many updates or innovations in Education. Educational innovations that occur in the field of education include, among others, education management. The purpose of this study was to determine the improvement of students' critical thinking. This research is a library research. Researcher data collection uses papers from scientific journals, theses and desertations, papers from conferences, previous theses and textbooks. The results of classical data analysis showed an increase from the lowest $6.18 \%$ to the highest $16.3 \%$ with an average of $34.08 \%$. The average student learning outcomes using the quantum learning model before using the quantum learning model were $70.04 \%$ and after using the quantum learning model increased to $81.55 \%$. It can be concluded that the quantum learning model can improve student learning outcomes and critical thinking in the PPKn subject.
\end{abstract}

Keywords: Quantum Learning, Critical Thinking.

\begin{abstract}
ABSTRAK
Pendidikan dapat diartikan sebagai suatu proses atau aktivitas yang bertujuan agar tingkah laku manusia yang mengalami Pendidikan terjadi perubahan-perubahan. Belakangan ini Pendidikan telah banyak melakukan perbaharuan atau inovasi Pendidikan. Inovasi Pendidikan yang terjadi dalam bidang Pendidikan tersebut, antara lain adalah dalam management Pendidikan. Tujuan penelitian ini adalah untuk mengetahui Peningkatkan berpikir kritis siswa. Peneltian ini adalah penelitian kepustakaan ( Library Research ), Pengumpulan data peneliti menggunakan Paper dari Journal Ilmiah, Thesis dan Desertasi, Paper dari conference, Skripsi terdahulu dan buku textbook. Hasil analisis data secara klasikal menunjukan peningkatan dari yang terendah 6,18\% sampai dengan yang tertinggi $16,3 \%$ dengan rata-rata $34,08 \%$. Rata-rata hasil belajar siswa dengan menggunakan model pembelajaran quantum learning sebelum menggunakam model pembelajaran quantum learning yaitu $70,04 \%$ dan sesudah menggunakan model pembelajaran quantum learning meningkat menjadi $81,55 \%$. Hal ini dapat disimpulkan bahwa model pembelajaran quantum learning dapat meningkatkan hasil belajar dan berpikir kritis siswa pada mata pelajaran PPKn.
\end{abstract}

Kata Kunci : Quantum Learning, Berpikir Kritis. 
$2 \mid$ Ahmad Yanuar Syauki1, Muhtaji², dan Iroh Napiroh33, Model Pembelajaran

Quantum Learning Terhadap Berpikir Kritis Siswa Pada Mata Pelajaran PPKn

\section{PENDAHULUAN}

Pendidikan Pancasila dan Kewarganegaraan merupakan wahana untuk mengembangkan dan melestarikan nilai luhur dan moral yang berakar pada budaya bangsa Indonesia yang diharapkan dapat diwujudkan dalam bentuk perilaku dalam kehidupan sehari-hari siswa, baik sebagai individual maupun sebagai anggota masyarakat, warga negara dan sebagai makhluk ciptaan tuhan yang maha esa.

Pendidikan dapat diartikan sebagai suatu proses atau aktivitas yang bertujuan agar tingkah laku manusia yang mengalami Pendidikan terjadi perubahanperubahan. Belakangan ini Pendidikan telah banyak melakukan perbaharuan atau inovasi Pendidikan. Inovasi Pendidikan yang terjadi dalam bidang Pendidikan tersebut, antara lain adalah dalam management Pendidikan.

Salah satu cara yang dapat ditempuh berkaitan dengan inovasi tugas mengajar guru adalah guru hendaknya mempunyai kemampuan dalam mengembangkan metode mengajarnya. Metode mengajar dapat diartikan sebagai suatu cara atau Teknik yang dipakai oleh guru dalam menyajikan bahan ajar kepada siswa untuk mencapai tujuan pengajaran. Khususnya dalam hal ini adalah metode untuk menunjang proses belajar mengajar pelajaran PPKn.

Model Pembelajaran Quantum Learning pertama kali diterapkan disebuah Lembaga pembelajaran yang terletak di Kirkwood Meadows, Negara bagian California Amerika Serikat. Pada awal penerapan dilakukan pada tahun 1982 oleh Bobby Deporter disekolah Supercamp. Di Supercamp ini menggabungkan rasa percaya diri keteram[ilan belajar, dan keterampilan berkomunikasi dalam lingkungan yang menyenangkan.

(C) 2021, Tulip, Jurnal Tulisn IImiah Pendidikan. STKIPB e-ISSN: 2807-4114
Quantum didefinisikan sebagai interaksi yang mengubah energi menjadi cahaya. Semua kehidupan adalah energi. Rumus yang terkenal dalam fisika kuantum adalah massa kali kecepatan cahaya kuadrat sama dengan energi atau baisa dikenal dengan $\mathrm{E}=\mathrm{mc} 2{ }^{1}$ Tubuh manusia secara fisik adalah materi. Sebagai pelajar, tujuannya adalah untuk meraih sebanyak mungkin cahaya, interaksi, hunbungan, inspirasi, agar menghasilkan cahaya.

Dapat didefinisikan bahwa pengubahan bermacam - macam yang ada didalam kelas atau tempat yang dapat dijadikan tempat belajar. Interaksi interaksi ini mencakup unsur - unsur untuk belajar efektif yang dapat mempengaruhi kesuksesan siswa. Interaksi - interaksi ini dapat mengubah kemampuan dan bakat alamiah siswa menjadi cahaya yang akan bermanfaat bagi mereka sendiri dan bagi orang lain.

\section{LANDASAN TEORI}

\section{Pengertian Model Pembelajaran Quantum Learning.}

Model Pembelajaran Quantum Learning pertama kali diterapkan disebuah Lembaga pembelajaran yang terletak di Kirkwood Meadows, Negara bagian California Amerika Serikat. Pada awal penerapan dilakukan pada tahun 1982 oleh Bobby Deporter disekolah Supercamp. Di Supercamp ini menggabungkan rasa percaya diri keteram[ilan belajar, dan keterampilan berkomunikasi dalam lingkungan yang menyenangkan.

Quantum didefinisikan sebagai interaksi yang mengubah energi menjadi cahaya. Semua kehidupan adalah energi. Rumus yang terkenal

\footnotetext{
${ }^{1}$ Udin Syaefudin, Inovasi Pendidikan (Bandung:

Afabeta, 2010) Hal: 127 .
} 
$3 \mid$ Ahmad Yanuar Syauki1, Muhtaji², dan Iroh Napiroh3, Model Pembelajaran

Quantum Learning Terhadap Berpikir Kritis Siswa Pada Mata Pelajaran PPKn

dalam fisika kuantum adalah massa kali kecepatan cahaya kuadrat sama dengan energi atau baisa dikenal dengan $\mathrm{E}=\mathrm{mc} 2 .^{2}$ Tubuh manusia secara fisik adalah materi. Sebagai pelajar, tujuannya adalah untuk meraih sebanyak mungkin cahaya, interaksi, hunbungan, inspirasi, agar menghasilkan cahaya.

Dapat didefinisikan bahwa pengubahan bermacam - macam yang ada didalam kelas atau tempat yang dapat dijadikan tempat belajar. Interaksi - interaksi ini mencakup unsur - unsur untuk belajar efektif yang dapat mempengaruhi kesuksesan siswa. Interaksi - interaksi ini dapat mengubah kemampuan dan bakat alamiah siswa menjadi cahaya yang akan bermanfaat bagi mereka sendiri dan bagi orang lain.

\section{Komponen Model Pembelajaran Quantum Learning.}

Komponen Model Pembelajaran Quantum Learning hampir sama dengan sebuah simfoni. Unsur - unsur dalam Quantum Learning. Model terdapat dalam dua kategori, yaitu Konteks dan Isi. Guru sebagai konduktor dari siswa - siswa yang sedang belajar, harus mengubah banyak bagian. Bagian Konteks meliputi pengubahan suasana, landasan, lingkungan dan rancangan belajar. Sedangkan bagian Isi meliputi pengubahan penyajian informasi / materi, fasilitas, keterampilan dan hidup.

\section{Prinsip Suggestologi}

Hampir mirip dengan proses accelerated learning, pemercepatan belajar : yakni proses belajar yang memungkinkan siswa belajar dengan kecepatan yang mengesankan, dengan

2 Udin Syaefudin, Inovasi Pendidikan (Bandung: Afabeta,2010) Hal: 127.

(C) 2021, Tulip, Jurnal Tulisn IImiah Pendidikan. STKIPB e-ISSN: 2807-4114 upaya yang normal, dan dibarengi kegembiraan. Suasana belajar yang efektif diciptakan melalui campuran antara lain unsur - unsur atau komponen - komponen hiburan, permainan, cara berpikir positif, dan emosi yang sehat.

Quantum Learning mencakup aspek - aspek penting dalam program Neurolinguistik (NLP), yaitu suatu penelitian tentang bagaimana otak mengatur informasi. Program ini meneliti hubungan antara Bahasa dan perilaku dan dapat digunakan untuk menciptakan jalinan pengertian siswa dan guru. Para pendidik dengan pengetahuan NLP mengetahui bagaimana menggunakan bahasa yang positif untuk meningkatkan tindakan tindakan positif. Faktor penting untuk merangsang fungsi otak yang paling efektif. Semua ini dapat pula menunjukkan dan menciptakan gaya belajar terbaik dari setiap orang.

Dalam pembelajaran Quantum Learning ada Lima ciri spesifik yang berguna untuk meningkatkan otak untuk memahami suatu informasi yang diberikan, Ciri- ciri tersebut adalah :

- Learning To Know yang artinya belajar untuk mengetahui.

- Learning To Do yang artinya belajar untuk melakukan

- Learning To Be yang artinya belajar untuk menjadi dirinya sendiri.

- Learning To Live Together yang artinya belajar untuk kebersamaan.

\section{Konsep Dasar Model \\ Pembelajaran Quantum Learning.}

Konsep Dasar Model

Pembelajaran dalam Quantum 
4| Ahmad Yanuar Syauki1, Muhtaji², dan Iroh Napiroh3, Model Pembelajaran

Quantum Learning Terhadap Berpikir Kritis Siswa Pada Mata Pelajaran PPKn

Learning dari berbagai teori dan strategi belajar yang digunakan antara lain :

- Teori otak kanan kiri

- Teori otak triune (3 in 1)

- Pilihan modalitas (Visual, Audtorial, dan Kinestetik)

- Teori kecerdasan ganda

- Pendidikan holistic (menyeluruh)

- Belajar berdasarkan pengalaman

- Belajar dengan symbol (metaphoric leraning)

- Simulasi / Permainan

- Peta pikiran (mind mapping).

\section{METODE}

Penelitian kepustakaan dan studi pustaka/riset pustaka meski bisa dikatakan mirip akan tetapi berbeda. Studi pustaka adalah istilah lain dari kajian pustaka, tinjauan pustaka, kajian teoritis, landasan teori, telaah putsaka (literature review), dan tinjauan teoritis. Yang dimaksud penelitian kepustakaan adalah penelitian yang dilakukan hanya berdasarkan atas karya tertulis, termasuk hasil penelitian baik yang telah maupun yang belum dipublikasikan ${ }^{3}$. Data yang digunakan sebagai berikut.

1. Sumber data primer pada penelitian ini merupakan data yang memuat tentang pengaruh model pembelajaran Quantum Learning terhadap berpikir kritis siswa pada pelajaran PPKn.

a. Belajar dan Faktor-Faktor yang Mempengaruhi. Jakarta: Rineka Cipta.

b. Teori Belajar dan Pembelajaran. Bogor: Ghalia Indonesia.

c. Teori Belajar dan

Pembelajaran.Jakarta: Prenadamedia Grup.

d. Paradigma Baru Pembelajaran. Jakarta: Kencana.

${ }^{3}$ Melfianora. (2017). Penulisan Karya Ilmiah dengan Studi Literatur. Pekanbaru. Hal 1.

(C) 2021, Tulip, Jurnal Tulisn IImiah Pendidikan. STKIPB e-ISSN: 2807-4114 e. Cooperatif Learning Teori dan Aplikasi Paikem. Yogyakarta: Pustaka Belajar.

f. Pembelajaran Kontekstual Konsep dan Aplikasi. Bandung: Refika Aditama.

g. Strategi Pembelajaran Berorientasi Standar Proses Pendidikan. Jakarta: Kencana Prenadamedia Grup.

h. Model Pembelajaran Inovatif dalam Kurikulum 2013.Yogyakarta: ArRuzz Media.

i. Metode Penelitian Pendidikan. Bandung: Pustaka Rahmat.

j. Penilaian Hasil Proses Belajar Mengajar. Bandung: Remaja Rosdakarya.

k. Kamus Istilah Karya Tulis Ilmiah. Jakarta: Bumi Aksara.

2. Sumber data sekunder

Data sekunder yaitu data yang telah dikumpulkan untuk maksud selain menyelesaikan masalah yang sedang dihadapi. Data ini dapat ditemukan dengan cepat. Dalam penelitian ini yang menjadi sumber data sekunder adalah artikel, jurnal, skripsi terdahulu yang relevan, serta situs di internet yang berkenaan dengan penelitian yang dilakukan ${ }^{4}$.

Berdasarkan tabel tersebut menunjukan bahwa adanya peningkatan hasil belajar dan berpikir kritis siswa melalui pembelajaran quantum learning pada pembelajaran PPKn. Rata-rata persentase peningkatan hasil belajar siswa dengan menggunakan model pembelajaran quantum learning mulai dari yang terendah $6,18 \%$ sampai dengan yang tertinggi $16,3 \%$ dengan rata-rata $34,08 \%$. Rata-rata hasil belajar siswa dengan menggunakan model pembelajaran quantum learning sebelum menggunakam model pembelajaran quantum learning yaitu

${ }^{4}$ Sugiyono. 2013. Metode Penelitian Kuantitatif Kualitatif Dan R\&D. Bandung: Alfabeta. Hal 137.

STKIPB JURNAL 
5| Ahmad Yanuar Syauki1, Muhtaji², dan Iroh Napiroh³, Model Pembelajaran

Quantum Learning Terhadap Berpikir Kritis Siswa Pada Mata Pelajaran PPKn

70,04\% dan sesudah menggunakan model pembelajaran quantum learning meningkat menjadi $81,55 \%$. Hal ini dapat disimpulkan bahwa model pembelajaran quantum learning dapat meningkatkan hasil belajar dan berpikir kritis siswa pada mata pelajaran PPKn.

\section{HASIL DAN PEMBAHASAN}

\section{Hasil}

Berdasarkan hasil analisis penelitian bahwa model Berdasarkan tabel tersebut menunjukan bahwa adanya peningkatan hasil belajar dan berpikir kritis siswa melalui pembelajaran quantum learning pada pembelajaran PPKn. Rata-rata persentase peningkatan hasil belajar siswa dengan menggunakan model pembelajaran quantum learning mulai dari yang terendah $6,18 \%$ sampai dengan yang tertinggi $16,3 \%$ dengan rata-rata $34,08 \%$. Rata-rata hasil belajar siswa dengan menggunakan model pembelajaran quantum learning sebelum menggunakam model pembelajaran quantum learning yaitu $70,04 \%$ dan sesudah menggunakan model pembelajaran quantum learning meningkat menjadi $81,55 \%$. Hal ini dapat disimpulkan bahwa model pembelajaran quantum learning dapat meningkatkan hasil belajar dan berpikir kritis siswa pada mata pelajaran PPKn.

\section{Pembahasan}

Berdasarkan hasil analisis penelitian bahwa model pembelajaran quantum learning dapat meningkatkan hasil belajar dan berpikir kritis siswa siswa pada mata pelajaran PPKn. Hasil penelitian diatas dapat dilihat bahwa setiap penelitian yang telah dilakukan memperoleh hasil persentase yang menunjukan adanya peningkatan hasil belajar dan berpikir kritis siswa, terlihat dalam kode data jurnal A1 skor pretes menunjukan data dari $76,6 \%$ ketuntasan klasikal menjadi $88,2 \%$ sehingga peningkatannya $11,6 \%$, kode data A2 menunjukan dari $66,82 \%$ menjadi

(C) 2021, Tulip, Jurnal Tulisn IImiah Pendidikan. STKIPB e-ISSN: 2807-4114
$73,46 \%$ dengan peningkatan mencapai $6,18 \%$, kode data A3 dari $66,7 \%$ menjadi $83 \%$ dengan peningkatan mencapai $16,3 \%$.

Belajar memerlukan kedekatan dengan materi yang hendak dipelajari, jauh sebelum bisa memahaminya. Belajar juga memerlukan kedekatan dengan berbagai macam hal, bukan sekedar pergaulan atau hafalan. Ketika kegiatan belajar bersifat aktif, peserta didik akan mengupayakan sesuatu. Dia menginginkan jawaban atas sebuah pertanyaan, membutuhkan informasi untuk memec ahkan masalah, atau mencari cara untuk mengerjakan tugas ${ }^{5}$.

Penilaian hasil belajar oleh pendidik memiliki fungsi untuk memantau kemajuan belajar, memantau hasil belajar dan mendeteksi kebutuhan perbaikan hasil belajar peserta didik secara berkesinambungan ${ }^{6}$.

Tes lebih cocok digunakan untuk mengetahui kemampuan siswa dalam aspek pengetahuan dan keterampilan (aspek kognitif dan aspek psikomotor), tidak cocok digunakan untuk mengukur sikap, karena sikap tidak dapat diinterpretasi kedalam benar atau salah, namun untuk mendapatkan deskripsi tentang profil sikap siswa. ${ }^{7}$

\section{PENUTUP}

\section{Simpulan}

Berdasarkan hasil analisis temuan dalam penelitian yang sudah dilakukan peneliti, dapat disimpulkan bahwa:

1. Berdasarkan hasil temuan dan pembahasan dalam sumber data berupa

\footnotetext{
5 Silberman, L. Melvin. (2013). Active Learning 101 Cara Belajar Siswa Aktif. Bandung : Nuansa Cendekia. Hal 27.

6 Widoyoko, Putro E. (2018). Penilaian Hasil Pembelajaran disekolah. Yogyakarta : Pustaka Pelajar. Hal 18.

7 Widoyoko, Putro E. (2018). Penilaian Hasil Pembelajaran disekolah. Yogyakarta : Pustaka Pelajar. Hal 65.
}

STKIPB JURNAL 
6 Ahmad Yanuar Syauki1, Muhtaji², dan Iroh Napiroh3, Model Pembelajaran

Quantum Learning Terhadap Berpikir Kritis Siswa Pada Mata Pelajaran PPKn

jurnal menunjukan adanya peningkatan hasil belajar dan berpikir kritis siswa. Hasil analisis data secara klasikal menunjukan peningkatan dari yang terendah dari yang terendah $6,18 \%$ sampai dengan yang tertinggi $16,3 \%$ dengan rata-rata $34,08 \%$. Rata-rata hasil belajar siswa dengan menggunakan model pembelajaran quantum learning sebelum menggunakam model pembelajaran quantum learning yaitu $70,04 \%$ dan sesudah menggunakan model pembelajaran quantum learning meningkat menjadi $81,55 \%$. Hal ini dapat disimpulkan bahwa model pembelajaran quantum learning dapat meningkatkan hasil belajar dan berpikir kritis siswa pada mata pelajaran PPKn.

2. Dari hasil jurnal penelitian bahwa model pembelajaran quantum learning pada pembelajaran PPKn dapat diterapkan disemua jenjang baik SD, SMP, maupun SMA. Karena model pembelajaran tersebut membuat peserta didik aktip dalam melakukan kegiatan, baik diskusi, tanya jawab, presentasi, dan membuat kesimpulan.

\section{Saran}

sehingga peneliti mengajukan beberapa saran untuk upaya perbaikan penelitian-penelitian serupa yang akan mendatang sebagai berikut:

1. Penelitian yang dilakukan ini hendaknya harus dilakukan teliti dan detail sehingga dapat meminimalisir hasil data yang kurang sesuai, juga pemilihan sumber data juga harus lengkap tanpa ada batasnya agar data yang dihasilkan lebih banyak serta kualitas penelitian ini dikategorikan baik.

2. Model pembelajaran quantum learning paling efektif jika pada saat proses pembelajaran adanya ketersediaan fasilitas atau sarana prasarana yang mendukung dalam proses pembelajaran, baik itu media ataupun yang lainnya agar tujuan dari proses pembelajaran dapat tercapai dengan baik.

(C) 2021, Tulip, Jurnal Tulisn Ilmiah Pendidikan. STKIPB e-ISSN: 2807-4114
3. Terlebih dengan kondisi dan situasi saat ini yang diakibatkan oleh adanya pandemi COVID 19 yang tidak tahu kapan selesainya, membuat peneliti kesulitan mencari sumber data yang melibatkan banyak orang atau terjun kelapangan jadi terhambat, akan tetapi waktu penelitian terus berjalan. Untuk itu antisipasi dari peneliti menyarankan jika ingin melakukan penelitian tanpa harus mencari sumber data melibatkan banyak orang ataupun terjun langsung ke lapangan bisa menggunakan penelitian yang seperti ini.

\section{DAFTAR PUSTAKA}

Kewarganegaraan Membangun Wrga Negara yang Demokratis Buku Pelajaran untuk SMP/MTs VI. Bandung : Grafindo Media Pratama

Arikunto Suharsimi, (2013) Prosedur Penelitian, Jakarta : PT Rineka Cipta

Bobby Deporter. (2011). Quantum Learning Membiasakan Belajar Nyaman dan Menyenangkan. Bandung: Kaifa

Deni kurniawan Terpadu Tematik. (2014). Teori, Praktik dan Penilaian. Bandung: Alfabeta

Depdiknas. (2004). Konsep Pendidikan Kewarganegaraan. Depdiknas. Jakarta

Diantama, Suarifqi. (2018). Metode Penelitian Pendidikan. Kota Bandung: Pustaka Rahmat

Nasution.(1972). Psikologi Pengajaran. Bandung : Remaja Roesda karya

Purwanto. (2014). Evaluasi Hasil Belajar. Yogyakarta : Pustaka Belajar

Sudjana, Nana. (2015) Penilaian Hasil Proses Belajar Mengajar. Bandung: Remaja Rosda karya 
7| Ahmad Yanuar Syauki1, Muhtaji², dan Iroh Napiroh33, Model Pembelajaran Quantum Learning Terhadap Berpikir Kritis Siswa Pada Mata Pelajaran PPKn

Sugiyono. (2014). Metode Penelitian Kuantitatif Kualitatifdan $R \& D$. Bandung: Alfabeta

Suyatno. (2004). Menjelajahi Pembelajaran Inovatif. Sidoarjo : Masmedia Busana Pustaka

Tirtarahardja Umar, dkk. (2008). Pengantar Pendidikan. Jakarta : PT.Rieneka Cipta

Udin syaefudin. (2010). Inovasi Pendidikan. Bandung: Alfabeta

Zakiah linda, dan Lestari Ika. (2019). Berfiir Kritis dalam konteks Pembelajaran. Bogor : Erzatama Karya Abadi 